\title{
Teoria da Mente e compreensão da representação gráfica de conteúdos mentais ("balões de pensamento")
}

\author{
Eduardo B. Ottoni \\ Cláudia Fernanda Rodriguez. \\ Janaína Corazza Barreto \\ Universidade de São Paulo
}

\begin{abstract}
RESUMO
Estudou-se a ontogênese da Teoria da Mente (atribuição de pensamentos e conteúdos mentais a outros indivíduos) por meio da representação gráfica de "balões de pensamento", examinando-se indicadores de diferentes estágios de desenvolvimento, como a compreensão de "falsas crenças" (conteúdos mentais conflitantes entre si ou com a realidade) e de ordens mais complexas de representação (pensamentos sobre pensamentos). Crianças de 3 a 13 anos de idade responderam a questões associadas aos tópicos: "pensamento X realidade" (contraste entre as propriedades dos objetos reais e a privacidade dos pensamentos), pensamentos diferentes sobre o mesmo objeto (possibilidade de pessoas diferentes terem idéias distintas sobre algo cuja real natureza é desconhecida), "falsa crença" (entendimento de que outros podem ter uma representação incorreta, quando é conhecida a correta) e representações de $2^{\mathrm{a}}$ e $3^{\mathrm{a}}$ ordem. Uma compreensão da representação gráfica de conteúdos mentais começa a aparecer de forma significativa por volta dos 5 anos e se consolida aos 7 anos de idade. A compreensão da situação envolvendo "falsa crença" surge, em alguns casos, entre 4 e 5 anos e é generalizada entre as crianças de 9 anos, idade em que começam a ser capazes de descrever verbalmente representações de $2^{\mathrm{a}}$ e $3^{\mathrm{a}}$ ordens.
\end{abstract}

Palavras-chave: Teoria da Mente; balões de pensamento; falsa crença

\section{ABSTRACT \\ Theory of Mind and understanding of graphical depictions of mental content ("thought bubbles")}

The ontogeny of the Theory of Mind (attribution of thoughts and mental contents to other people) was studied using the graphic depiction of "thought bubbles", examining indicators of different developmental stages, such as the understanding of "false beliefs" (mental contents conflicting among themselves or with reality) and of higher-order representations (thoughts about thoughts). Children aged from 3 to 13 years answered questions about "thought versus reality" (contrast between the properties of real objects and the privacy of thoughts), different thoughts about the same object (possibility of different people having different ideas about something whose actual nature is unknown), false belief (understanding that others may hold an incorrect representation, when the correct one is known) and $2^{\text {nd }}$ and $3^{\text {rd }}$ order representations. The understanding of graphical depictions of mental content was first significantly observed around 5 years of age, and becomes established at 7 . Understanding of situations involving "false belief" was observed, in some cases, between 4 and 5 years, and was widespread among 9-year-olds - the age when they start being able to verbally describe $2^{\text {nd }}$ and $3^{\text {rd }}$ order representations.

Keywords: Theory of Mind; thought bubbles; false belief

A expressão "Teoria da Mente" foi cunhada por David Premack para designar o comportamento que consiste em atribuir estados mentais a outros indivíduos e usar estes estados inferidos para predizer e explicar seu comportamento. Premack e Woodruff (1978) utilizaram o termo pela primeira vez ao discutir as capacidades cognitivas dos chimpanzés - perguntando-se se, tal como os seres humanos fazem, estes animais pensam em seus conspecíficos como sistemas intencionais. As evidências da primatologia de campo, porém, dificilmente vão além do anedótico - e a opção entre as explicações mais "ricas" e as mais "parcimo- 
niosas" depende, para Premack, de experimentação controlada. Para este autor, entretanto, os chimpanzés exibiriam apenas uma capacidade muito limitada de atribuição de estados mentais (possivelmente amplificada nos animais com treino de manipulação de conceitos no laboratório), capacidade esta que só se manifestaria plenamente em seres humanos a partir dos 4 anos de idade, sendo então limitada apenas pelo número de aninhamentos hierárquicos (pensamentos sobre pensamentos sobre pensamentos...) que a memória pode processar (Premack, 1988).

Enquanto a questão da atribuição de estados mentais em primatas não-humanos continua sendo um tema polêmico, o termo "Teoria da Mente" foi prontamente assimilado pelos pesquisadores do desenvolvimento cognitivo humano, num cenário de crescente interesse pela ontogênese das capacidades associadas à "cognição social", ou seja, de mecanismos cognitivos especializados para a interação social. Muitos dos estudiosos contemporâneos do autismo, por exemplo, caracterizam esta síndrome como uma incapacidade ou deficiência na aquisição de uma Teoria da Mente (Boucher, 1996; Phillips, Baron-Cohen \& Rutter, 1998).

Duas linhas de estudo se destacam nesse contexto: os experimentos sobre "falsa crença" e os voltados para a ontogênese da "enganação tática" em crianças. Nesta última abordagem, em uma situação em que os sujeitos tinham de esconder um objeto de um confederado ("cúmplice") do pesquisador, La Frenière (1988) constatou não apenas que o sucesso na tarefa (enganar o "cúmplice") estava significativamente correlacionado com a idade, mas ainda que a estratégia comportamental variava: as crianças mais novas (até 48 meses) eram incapazes de ocultar informação - algumas inclusive apontando alegremente o local do esconderijo; a estratégia mais freqüente de enganação (até os 6 anos, a amostra mais velha) era a inibição (supressão de dicas comportamentais, nem sempre totalmente eficaz), mas a ocorrência de simulação (fornecimento deliberado de dicas falsas) vai aumentando com a idade.

No experimento clássico sobre "falsa crença", Wimmer e Perner (1983) observaram que crianças até quatro anos de idade parecem ter dificuldade em compreender que diferentes pessoas possam ter representações distintas de uma mesma realidade. Neste experimento, mostrou-se aos sujeitos (3-9 anos) uma encenação em que o protagonista escondia um objeto que posteriormente, na sua ausência e sem seu conhecimento, era transferido para um local diferente. Quando era perguntado às crianças de 3 anos onde o prota- gonista iria procurar pelo objeto, elas ignoravam a falsa crença do protagonista e previram que ele iria procurar o objeto no local onde ele efetivamente estava, enquanto mais da metade das crianças de 4-6 anos de idade (e quase todas as mais velhas) previram que o protagonista iria procurar o objeto oculto no lugar incorreto (onde ele o havia escondido inicialmente). Este experimento foi extensivamente replicado, ganhando o apelido de "Problema de Sally-Anne" (Frith \& Frith, 1999).

No que se refere à idade crítica no desenvolvimento da Teoria da Mente, há discordâncias entre os pesquisadores, havendo inclusive autores que questionam a idéia de que haja uma idade cronológica específica, defendendo a posição de que a Teoria da Mente é um conceito como outro qualquer, cuja emergência estaria associada a um certo grau de desenvolvimento mental (Bradmetz, 1998). Um fator complicador está no fato de que diferentes procedimentos experimentais podem eliciar respostas positivas (i.e., indicadoras de uma Teoria da Mente operacional) a partir de diferentes idades. Szarkowicz (1999), por exemplo, observou que mais crianças eram capazes de demonstrar uma compreensão da "falsa crença" durante brincadeiras de esconde-esconde do que nas tarefas experimentais tradicionais - o que sugere que diferentes contextos sociais favorecem compreensões representacionais qualitativamente distintas.

\section{OBJETIVOS}

A presente pesquisa teve por objetivo estudar a ontogênese da Teoria da Mente em crianças e adolescentes por meio do uso de representações gráficas convencionais destes conteúdos, os "balões de pensamento" das histórias em quadrinhos.

Para tal, antes de tudo, fez-se necessário testar a própria ferramenta: embora os "balões de pensamento" (thought bubbles) das histórias em quadrinhos (uma forma de representação gráfica de conteúdos mentais amplamente difundida em nossa cultura) tenham sido ocasionalmente utilizados como estímulos em experimentos psicológicos diversos, o desenvolvimento desta compreensão em si praticamente não foi estudado.

Wellman, Hollander e Schult (1996) constataram que poucos pré-escolares de 3 ou 4 anos sabiam o que era um balão de pensamento sem instruções; entretanto, após lhes ser explicado que os balões mostravam "o que alguém está pensando", a grande maioria foi capaz de decodificar adequadamente esta forma de representação do pensamento em diversos contextos. 
Para os autores, a facilidade com que estas crianças compreenderam esta forma de representação gráfica sugere que os balões de pensamento capturam de maneira muito "adequada" nossos conceitos intuitivos sobre os pensamentos e que estes são compartilhados mesmo por crianças muito pequenas. Uma possível interpretação complementar para os casos de entendimento "tardio" (depois da explicação) pelos sujeitos seria a de que, para aquelas crianças, a compreensão dos balões de pensamento se encontre em sua "Zona de Desenvolvimento Proximal" (Vygotsky, 1984).

No presente estudo, os balões de pensamento foram utilizados para estudar dois importantes indicadores de diferentes estágios no desenvolvimento da Teoria da Mente: a compreensão de "falsas crenças" (conteúdos mentais conflitantes entre si ou com a realidade) e a de ordens mais complexas de aninhamento hierárquico das representações (pensamentos sobre pensamentos). Procurou-se abordar a questão de formas complementares, pela avaliação da compreensão de estímulos (ilustrações) apresentados aos sujeitos e pela análise de representações gráficas produzidas pelos sujeitos a partir de estímulos verbais. Este artigo relata a primeira parte da pesquisa, envolvendo a compreensão de estímulos gráficos representando pensamentos.

\section{METODOLOGIA}

Os sujeitos foram crianças de 3 a 13 anos de idade, distribuídos em amostras de 3, 5, 7, 9, 11 e 13 anos completos, com 10 meninos e 10 meninas em cada uma. As entrevistas foram realizadas em sessões individuais.

A compreensão da representação gráfica do pensamento e, subsequientemente, de situações envolvendo falsas crenças ou representações mentais de $2^{\mathrm{a}}$ e $3^{\mathrm{a}}$ ordem, foram avaliadas através das descrições verbais produzidas pelas crianças acerca de ilustrações utilizando balões de pensamento. Os cartões contendo as ilustrações reproduzidas na Figura 1 foram apresentados, um a um, sempre na mesma sequiência, e suas descrições pelas crianças foram registradas literalmente e categorizadas em termos de compreensão adequada ou não do conceito-chave testado através de cada ilustração, conforme indicado na página a seguir.

Questões 1-2: Compreensão da representação gráfica de conteúdos mentais através dos balões de pensamento: a Ilustração 1 foi utilizada com o objetivo de testar a simples compreensão do uso dos balões (pergunta: "o que é isso?", indicando-se o balão). No caso de respostas incorretas a esta questão, em particular, era explicado que o balão mostrava "o que a pessoa está pensando" - e as conseqüências desta orientação foram aferidas através da resposta à questão seguinte (que se seguiu à apresentação da Ilustração 2). A apresentação da Ilustração 2 foi seguida de perguntas que visavam verificar até que ponto a criança distinguia as propriedades do cachorro "real" das do gato "imaginário" ("pode-se pegar o gato/o cão?"; "alguém mais pode ver o gato/o cão?"); além de abordar novamente a compreensão dos balões de pensamento através um enfoque distinto, este teste permitiu avaliar o efeito da explicação da experimentadora (quando necessária) sobre a compreensão da criança.

Questões 3-4: Investigou-se aqui a compreensão de situações envolvendo "falsas crenças", solicitando às crianças que descrevessem duas ilustrações nas quais: (A) há pensamentos conflitantes sobre o conteúdo desconhecido de um pacote de presente (Ilustração 3) e (B) há uma discrepância entre a realidade, conhecida da criança (cachorrinho com latido forte) e a representação pelo personagem que ouve o cão sem vê-lo (Ilustração 4). A comparação entre estas diferentes situações decorreu das observações de Wellman e cols. (1996) de que crianças que não são bem sucedidas nos testes convencionais de "falsa crença" exibem um desempenho melhor em situações em que a "verdade" não é conhecida por elas.

Questões 5-6: Finalmente, ao solicitar às crianças que descrevessem o conteúdo das Ilustrações 5-6, a representação do pensamento por meio de "balões" foi utilizada para aferir a capacidade das crianças de descrever verbalmente situações envolvendo representações de $2^{\mathrm{a}}$ e $3^{\mathrm{a}}$ ordens, ou "pensamentos sobre pensamentos". Foram consideradas corretas as descrições que traduziam adequadamente o aninhamento hierárquico dos balões ("Menino pensando em menina que pensa em menino...").

\section{RESULTADOS E DISCUSSÃO}

As figuras a seguir referem-se às respostas em cada uma das 6 amostras (faixas etárias: 3 / 5/7/9/11/ 13 anos; Figura 2) para as 6 questões do experimento (Figura 3).

Nas respostas das crianças de 5 anos de idade, aparecem pela primeira vez acertos na Questão 4, mas nas duas últimas questões nenhuma resposta dos sujeitos nesta faixa etária pôde ser considerada correta. Apenas a partir dos 7 anos ocorreram acertos nas Questões 5 e 6, e os erros na Questão 1 só desapareceram por completo entre as crianças a partir de 9 anos. 

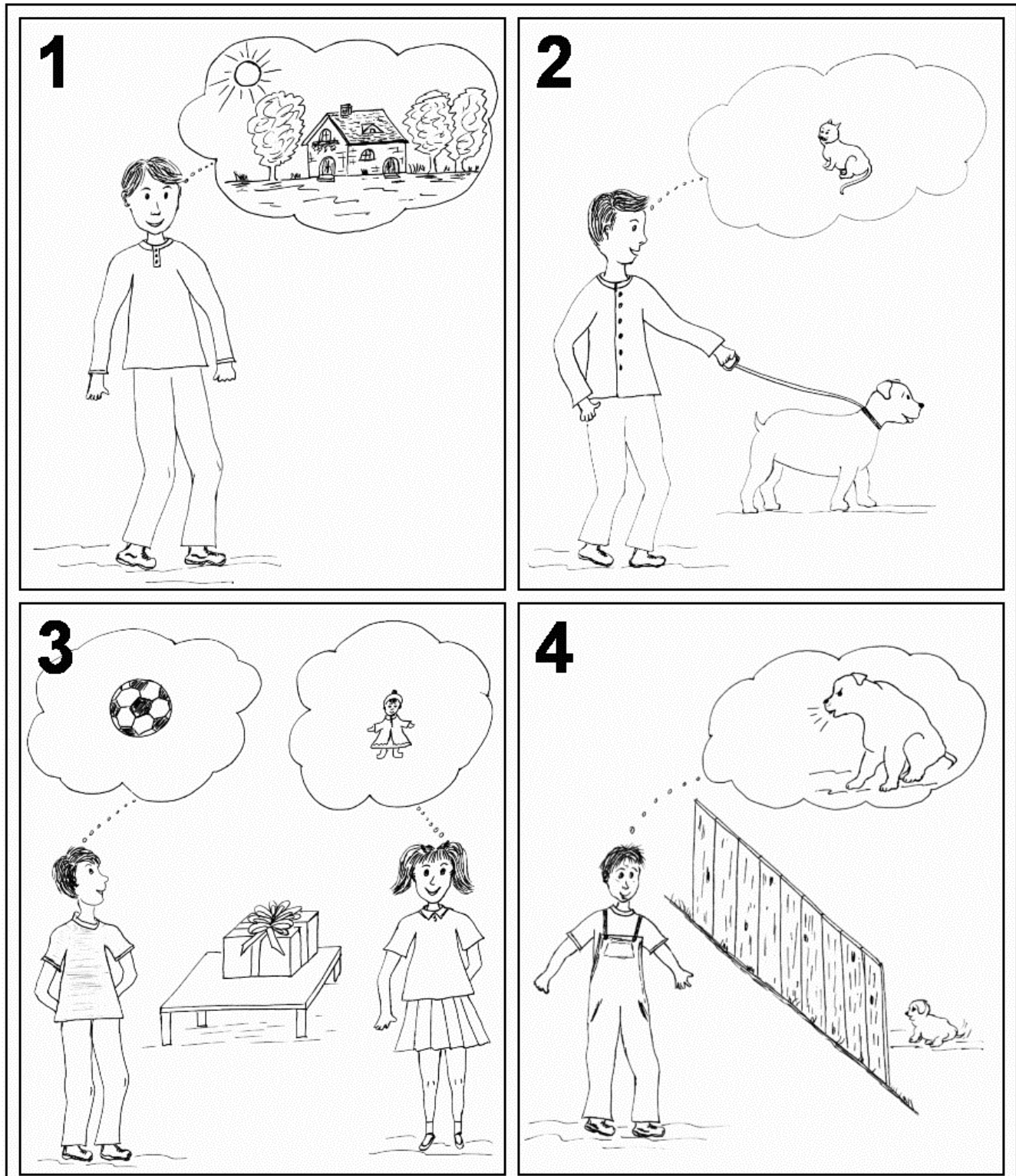

\section{5}
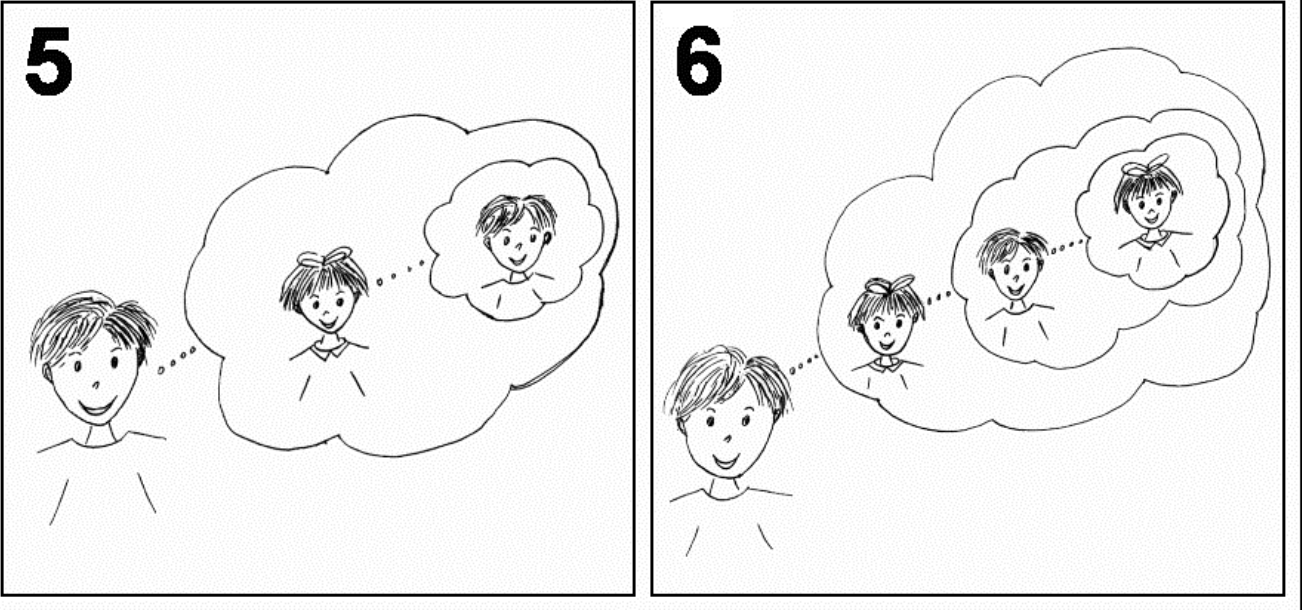

Figura 1. llustrações 1 a 6 , empregadas como estímulos (v. texto). 


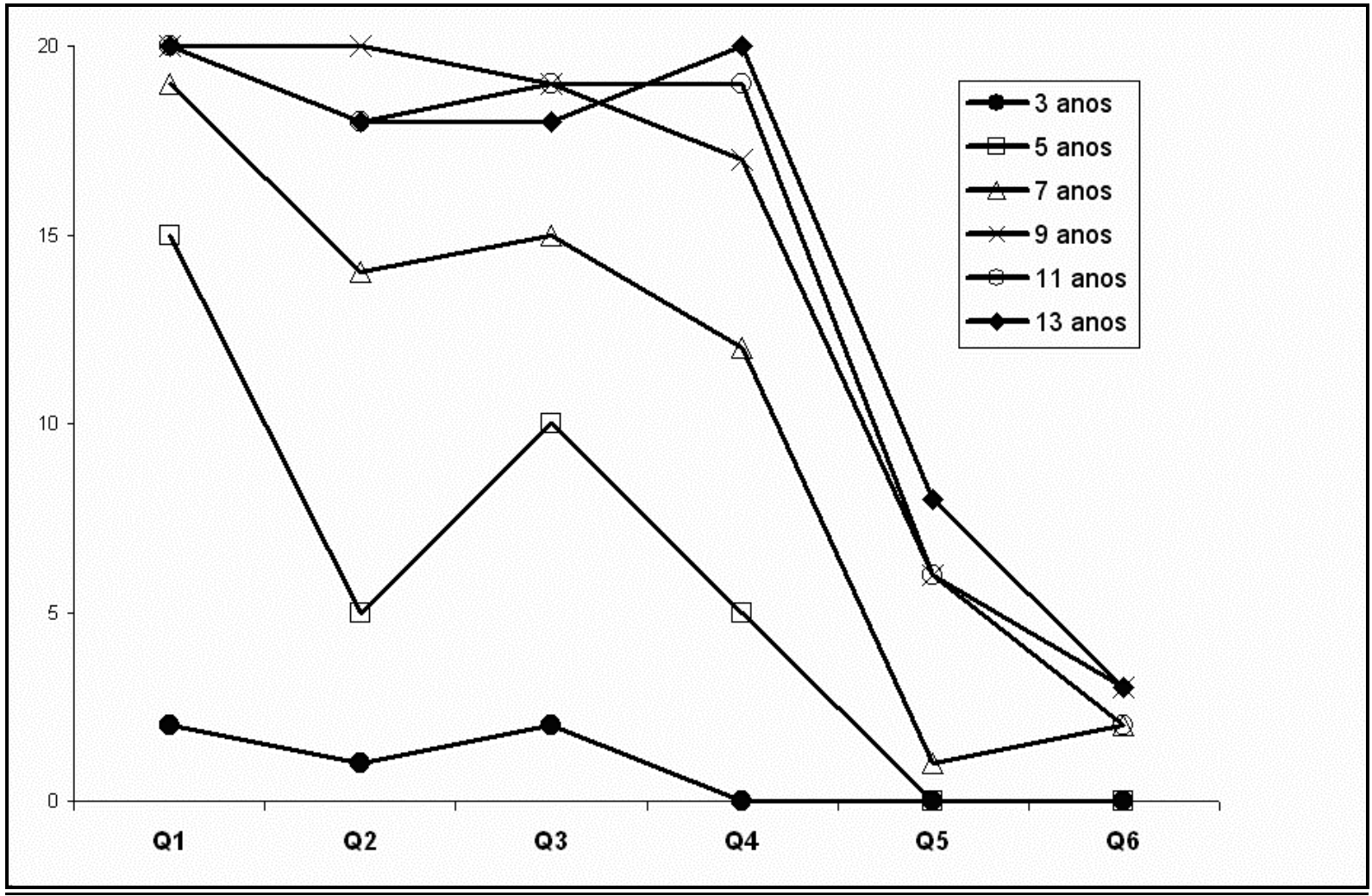

Figura 2. Freqüências de acerto nas Questões 1 a 6, por faixas etárias.

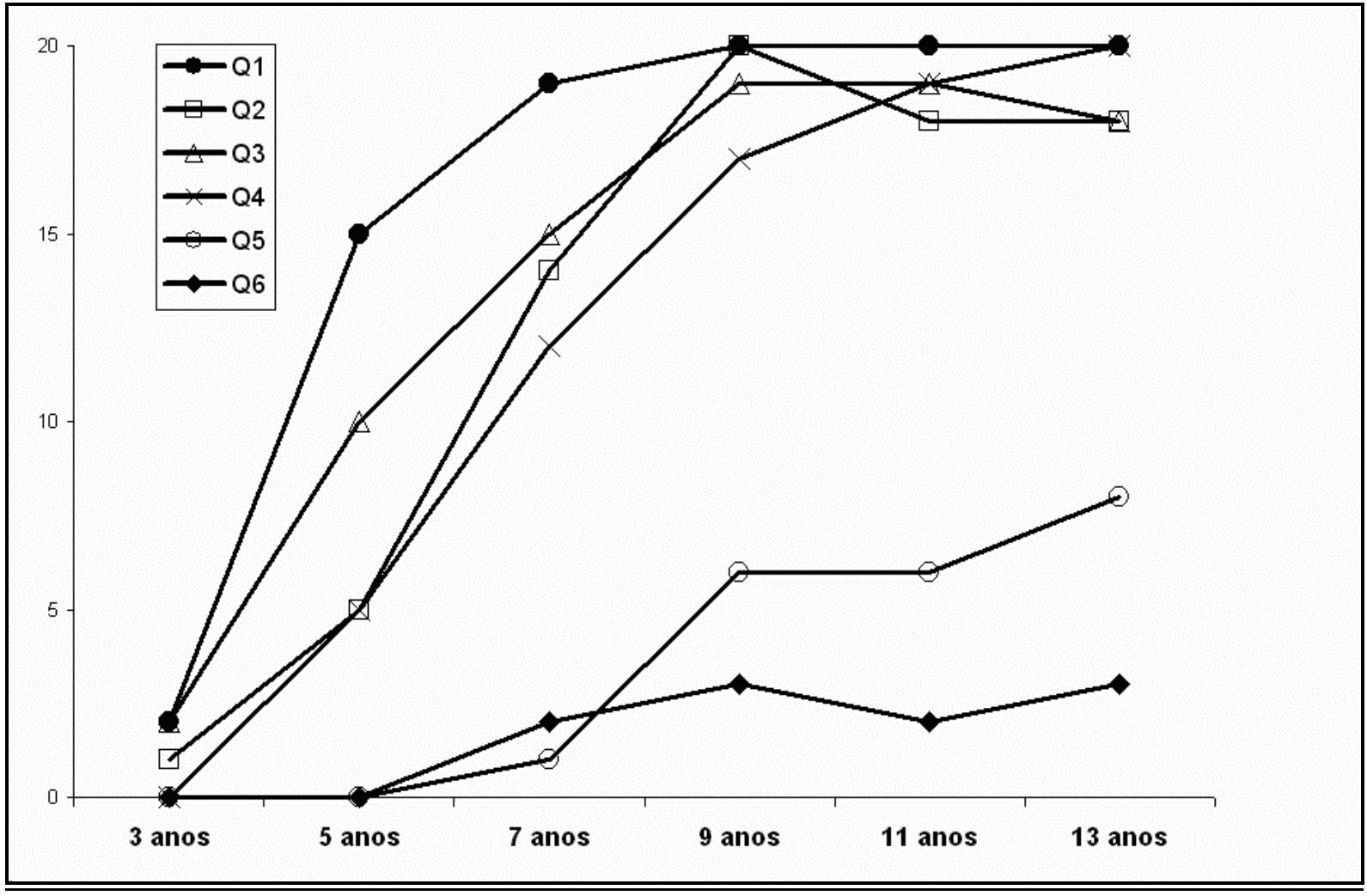

Figura 3. Freqüências de acerto por Questões, nas diferentes faixas etárias. 
Os gráficos das Figuras 4 e 5 mostram mais detalhadamente o desempenho das crianças nas Questões
5 e 6, para as amostras a partir dos 7 anos (as crianças mais jovens sequer compreenderam estas perguntas).

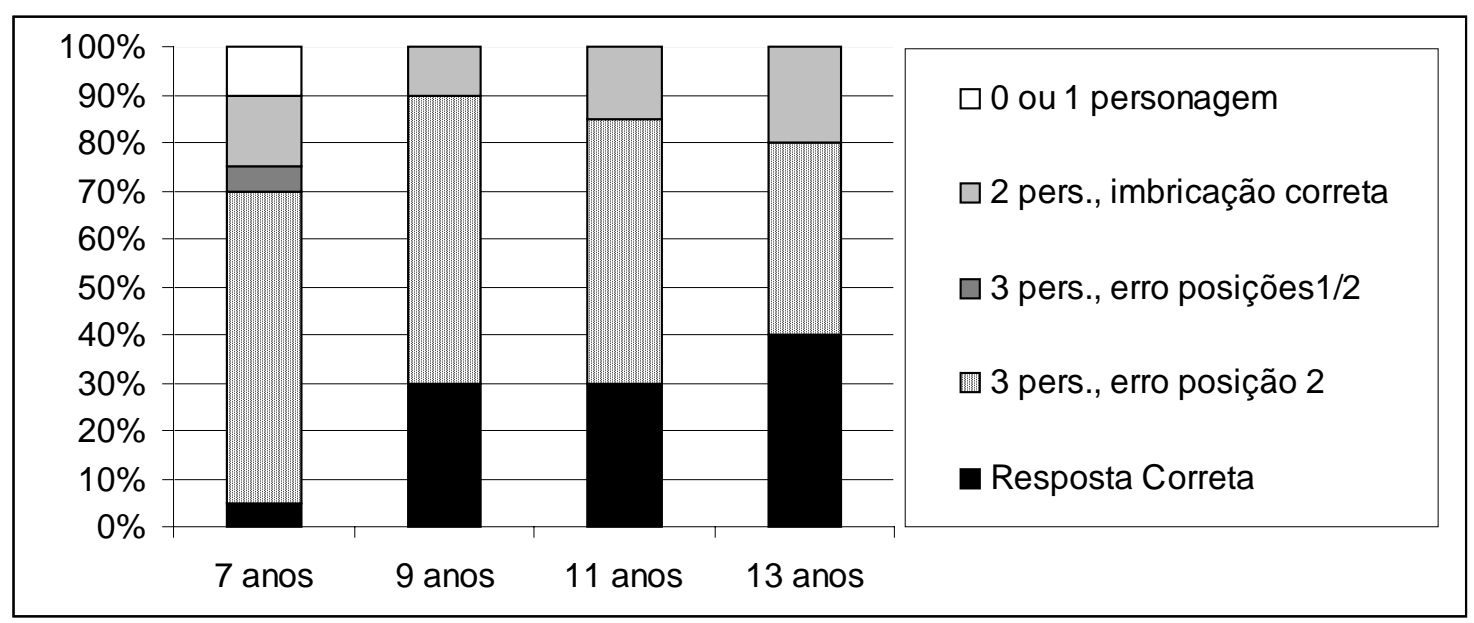

Figura 4. Categorização das respostas à Questão 5.

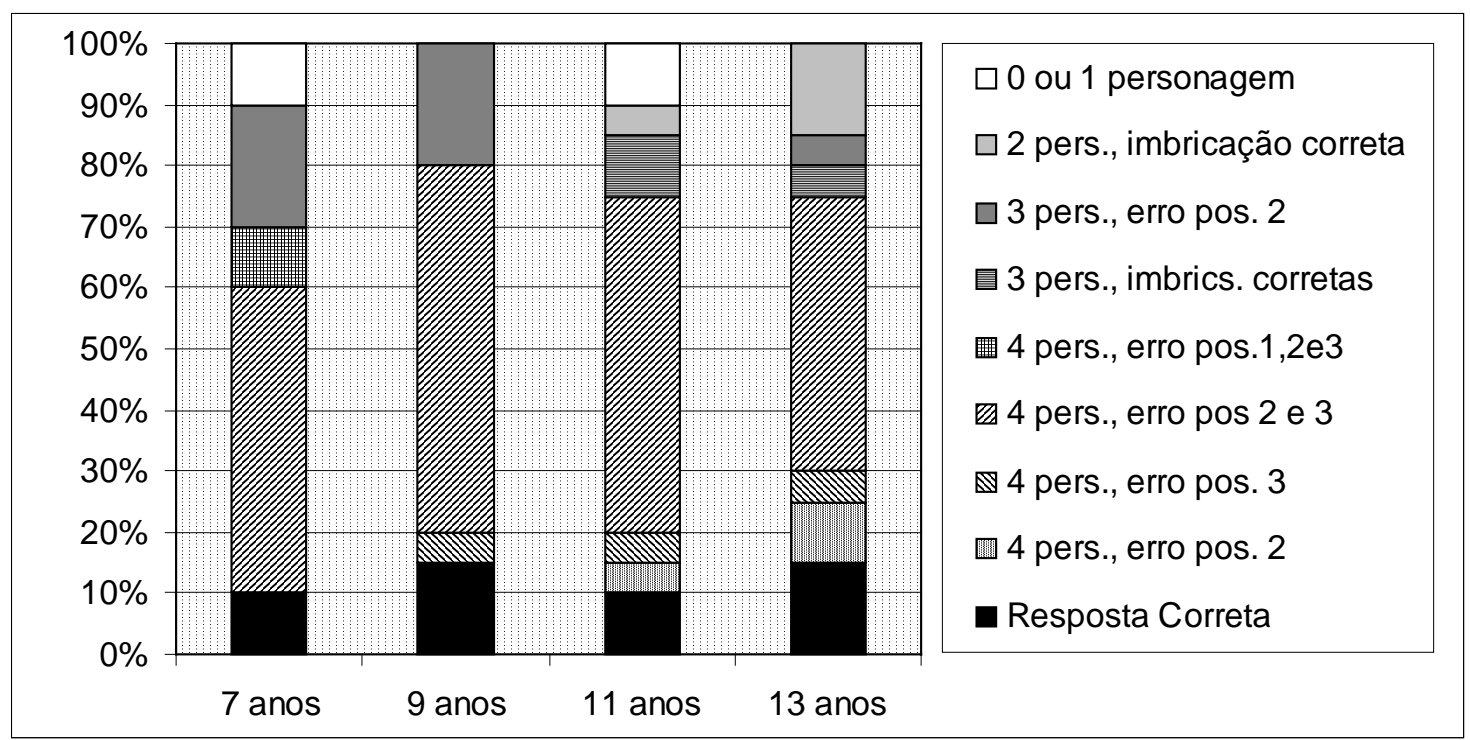

Figura 5. Categorização das respostas à Questão 6.

Para a análise dos erros na Questão 5, sintetizada na Figura 4, os critérios utilizados foram o número de personagens que a criança mencionava em sua resposta e como ela descrevia o "aninhamento" hierárquico dos pensamentos. As respostas registradas foram categorizadas conforme indicado a seguir (incluídas apenas as combinações efetivamente observadas):

A. Respostas com o número errado de personagens:

- Erro A1: 0 ou 1 personagem (Ex: "Ai, esse menino é o mesmo que esse? Eu não sei...”).
- Erro A2: 2 personagens, aninhamento correto (Ex: "Menino pensando na irmã").

B. Respostas erradas com o número correto (3) de personagens:

- Erro B1: erro de aninhamento nas posições 1, 2 e 3 (sem aninhamento hierárquico) (Ex: "Um menino, uma menina e um menino").

- Erro B2: Apenas aninhamentos de primeira ordem (com ou sem erros no número de personagens (Exs: "É um menino pensando numa menina e uma menina pensando num menino"; Interação em Psicologia, Curitiba, jul./dez. 2006, (10)2, p. 225-234 
"Ele está pensando em uma menina e em um menino").

C. Respostas consideradas corretas (3 personagens, aninhamentos hierárquicos corretos) (Ex: "Ele está pensando que uma menina está pensando nele").

No gráfico da Figura 5, as respostas foram categorizadas da seguinte maneira:

A. Respostas com o número errado de personagens:

- Erro A1: 0 ou 1 personagem.

- Erro A2: 2 personagens, aninhamento correto (Ex: "Ela está pensando em ter um namorado").

- Erro A3: 3 personagens, erro de aninhamento na posição 2 (apenas 1 aninhamento correto) (Ex: "Ele está pensando em ter duas irmãs").

- Erro A4: 3 personagens, aninhamento corretos (Ex:"Ele está pensando que ela está pensando nele também").

B. Respostas erradas com o número correto (4) de personagens:
- Erro B1: erros de aninhamento nas posições 1,2 e 3 (nenhum aninhamento correto) (Ex: "Um menino, uma menina, um menino e outra menina").

- Erro B2: erros de aninhamento nas posições $2 \mathrm{e}$ 3 (Ex: "Ele está pensando na menina, a menina está pensando no menino e o menino, pensando na menina").

- Erro B3: erro de aninhamento na posição 3 (Ex: "Ele está pensando que ela está pensando nele e ele está pensando nela").

- Erro B4: erro de aninhamento na posição 2 (Ex: "O menino está pensando na menina e ela está pensando que ele está pensando nela também").

C. Respostas consideradas corretas (4 personagens, aninhamentos hierárquicos corretos) (Ex: "Ele querendo que ela esteja pensando que ele está pensando nela").

A Tabela 1 mostra as diferenças encontradas na comparação entre as amostras contíguas para cada questão (Teste de Fisher, unilateral).

Tabela 1. Comparação entre as amostras (por faixa etária) quanto ao desempenho em cada questão (Fisher unilateral; * ${ }^{*}$ resultados significativos)

\begin{tabular}{lrrrrrr}
\hline AMOSTRAS & \multicolumn{1}{c}{ Q1 } & Q2 & Q3 & Q4 & \multicolumn{1}{c}{ Q5 } & Q6 \\
\hline A3 x A5 & $>0,0001^{*}$ & 0,0909 & $0,0069^{*}$ & $0,0236^{*}$ & 1 & 1 \\
A5 x A7 & 0,0909 & $0,0052^{*}$ & 0,0954 & $0,0268^{*}$ & 0,5 & 0,2436 \\
A7 x A9 & 0,5 & $0,0101^{*}$ & 0,0909 & 0,0776 & $0,0457^{*}$ & 0,5 \\
A9 x A11 & 1 & 0,2436 & 1 & 0,3023 & 1 & 0,5 \\
A11 x A13 & 1 & 1 & 0,5 & 0,5 & 0,3705 & 0,5 \\
\hline
\end{tabular}

$\mathrm{O}$ primeiro aspecto que este estudo procurou examinar referia-se à compreensão da linguagem dos quadrinhos pelas crianças, pré-requisito para o uso dos balões de pensamento como estímulos. Verificou-se que as crianças de 3 anos de idade não demonstraram entender estas representações gráficas adequadamente, em geral não respondendo de forma correta sequer às primeiras questões. A partir dos 5 anos de idade, a maioria das crianças parece estar familiarizada com a representação gráfica dos pensamentos (apenas $25 \%$ delas, nesta amostra, deram respostas incorretas à Questão 1) - e dos 9 anos em diante, as respostas às Questões 1 e 2 foram quase totalmente corretas.

A expectativa era que houvesse um grau de dificuldade crescente entre os blocos de questões, uma vez que foi examinada, inicialmente, apenas a compreensão do instrumento utilizado - a representação gráfica dos balões de pensamento $(\mathrm{Q} 1)$ - e a capaci- dade de diferenciar as qualidades de objetos do pensamento das qualidades de objetos reais (Q2). Em seguida, eram testados o entendimento de que é possível haver pensamentos diferentes sobre um mesmo objeto (Q3) e pensamentos em conflito com a realidade ("falsas crenças") (Q4). Por fim, as duas últimas questões (Q5-Q6) testavam a capacidade de compreensão de ordens mais complexas de aninhamento dos balões (representando "pensamentos sobre pensamentos"). Além disso, cada bloco de questões envolvia, em princípio, uma progressão na dificuldade (da primeira para a segunda questão do par).

Para as crianças de 5 anos, Q2 se parece ter sido um pouco mais difícil que Q3 (tendência nãosignificativa, Fisher unilateral.1 $>p>0,05$ ); este resultado sugere que nesta idade as crianças, embora já compreendam a linguagem gráfica para representar conteúdos mentais, ainda tenham dificuldades em 
diferenciar as propriedades de objetos do pensamento das propriedades de objetos reais na representação gráfica. Houve diferenças de desempenho entre Q1 e Q2 nas amostras de 5 (Fisher unilat., $\mathrm{p}=0,0019$ ) e 7 anos (Fisher unilat., $p=0,0457$ ). Estas foram as únicas diferenças significativas $(p<0,05)$ encontradas entre questões do mesmo bloco, para todas as faixas etárias.

Já com relação à compreensão de "falsas crenças", abordada pelas Questões Q3 (crenças conflitantes entre si, realidade desconhecida) e Q4 (crença conflitante com a realidade), a transição para uma compreensão adequada foi observada dos 3 aos 9 anos. Para Q3, foi encontrada uma diferença significativa de desempenho entre as amostras de 3 e 5 anos (Fisher unilateral, $\mathrm{p}=0,0069)$; para $\mathrm{Q} 4$, isto foi observado tanto entre as amostras de 3 e 5 anos $(\mathrm{p}=0,0236)$ quanto entre as de 5 e 7 anos ( $1=0,0268)$. Wellman $e$ cols. (1996) propõem a hipótese de que crianças que não entendem bem as situações de "falsa crença" (de terceiros) em conflito com uma "realidade" conhecida por elas podem sair-se melhor em tarefas onde não se sabe qual a alternativa verdadeira. Entretanto, ao comparar-se o desempenho das crianças nas questões Q3 (conteúdos imaginados do presente fechado) e Q4 (diferença entre o cão "imaginado" e o cão "real"), verifica-se apenas uma "tendência" pouco significativa neste sentido na amostra de 5 anos (Fisher unilateral, $\mathrm{p}=0,0954$ ), embora, até os 9 anos de idade o desempenho em Q3 tenha sido um pouco superior ao desempenho em Q4. Note-se que, para as crianças de 5 anos, Q3 se mostrou mais fácil que Q2 (diferença entre qualidades de objetos do pensamento e de objetos reais).

Embora algumas respostas erradas ainda ocorram (talvez em função de outras dificuldades, mais associadas à linguagem ou à atenção), o desempenho proficiente nas Questões relacionadas a divergências entre crenças e realidade parece se estabilizar a partir dos 9 anos.

Já a compreensão das representações envolvendo aninhamentos de ordens mais complexas está inteiramente ausente nas amostras de 3 e 5 anos e longe de se consolidar mesmo aos 13 anos, como mostraram os desempenhos nas duas últimas questões (Q5 e Q6). A maior diferença de desempenho na Questão 5 se deu dos 7 para os 9 anos, quando é atingido um patamar (baixo) que se mantém até a amostra mais velha deste estudo (13 anos). Apesar de não terem sido encontradas diferenças estatisticamente significativas entre os desempenhos nas Questões Q5 e Q6 em cada faixa etária, o número de acertos em Q6 foi (a partir dos 9 anos) sistematicamente inferior ao número de acertos em Q5, como seria de se esperar em função da ordem mais elevada de aninhamento (terceira $\mathrm{X}$ segunda ordem).

A análise dos erros nas respostas a estas questões mostrou que eles acontecem principalmente ao fazer os aninhamentos. Nos dois casos, a maior parte dos erros cometidos se deu ao fazer os aninhamentos de ordem superior, ou seja, o número de personagens estava correto, mas só havia o primeiro aninhamento o que provavelmente envolveu uma combinação de fatores, como limitações de memória e domínio da linguagem (mas também, talvez, motivação e atenção à tarefa).

A análise do padrão geral dos resultados mostra que as mudanças mais significativas no desenvolvimento da Teoria da Mente (para as faixas etárias testadas neste estudo) se dão até os 9 anos de idade. Dos 9 aos 13 anos, não houve mudanças notáveis.

Em relação à compreensão da representação gráfica do pensamento (Q1), a transição mais drástica ocorreu dos 3 para os 5 anos de idade.As maiores mudanças na diferenciação entre características de objetos do pensamento e da realidade (Q2) se deram dos 5 para os 7 e dos 7 para os 9 anos.

Já em relação à possibilidade de diferentes pessoas exibirem diferentes crenças a respeito da realidade (Q3), uma mudança significativa foi verificada dos 3 para os 5 anos de idade. Ainda quanto às "falsas crenças", mas no caso de crença conflitante com a realidade (Q4), as maiores mudanças ocorreram dos 3 para os 5 e dos 5 para os 7 anos de idade.

Em resumo, as faixas etárias em que se concentraram as mudanças conceituais que permitem a compreensão dos aspectos fundamentais para uma Teoria da Mente são as mais novas, até os 9 anos: a compreensão das representações gráficas e das diferentes qualidades do pensamento e da realidade parece sólida após esta idade, mas mesmo depois dos 13 anos ainda há dificuldades relativas às representações de ordens de aninhamento mais complexas.

A investigação a respeito do instrumento usado na pesquisa mostrou que as crianças mais novas - em particular, as da amostra de 3 anos - ainda não compreendem bem a representação gráfica do pensamento pelos balões, o que limita a possibilidade de uso da ferramenta nesta faixa etária. Para crianças acima desta idade, por outro lado, o instrumento mostrou-se bastante promissor. 


\section{CONCLUSÃO}

Tendo por objetivo o estudo da ontogênese da Teoria da Mente, foi inicialmente investigado o próprio instrumento a ser utilizado. Verificou-se que a compreensão da representação gráfica de conteúdos mentais começa a aparecer significativamente nas crianças de 5 anos de idade e se consolida a partir dos 7 anos de idade. Em outras palavras, foi constatado que antes dos 5 anos poucas crianças entendem o que é um "balão de pensamento", assim como mostrou a pesquisa de Wellman e cols. (1996). Entretanto, estes autores relataram uma diferença significativa neste aspecto, após o fornecimento de instruções, o que não foi claramente observado no presente experimento.

A compreensão da situação envolvendo "verdadeira X falsa crença" - sem conhecimento de qual a verdadeira (conteúdos mentais conflitantes entre si) aparece entre os 4 e 5 anos e depois cresce gradualmente até os 9 anos (a maioria das crianças já responde adequadamente aos 7 anos). Este resultado vai ao encontro do experimento clássico de Wimmer e Perner (1983), que observaram dificuldades nessa compreensão de "falsas crenças" até os 4 anos de idade.

A compreensão de crenças (explicitamente) conflitantes com a realidade aumenta gradualmente até os 9 anos (a partir daí, a quase totalidade das respostas é correta).

A capacidade das crianças de descrever verbalmente situações envolvendo representações de $2^{\mathrm{a}}$ e $3^{\mathrm{a}}$ ordens aparece aos 9 anos, não sofrendo mudanças significativas nas amostras mais velhas. Mesmo assim, a discussão de "pensamentos sobre pensamentos" ainda se mostra difícil mesmo para as crianças de 13 anos de idade, o que se confirmou pela queda de acertos com a inclusão de mais um balão de pensamento; isso provavelmente decorre não de limitações na Teoria da Mente, em si, mas de limitações atencionais e linguísticas no manejo de sequiências de imbricação mais longas.

\section{REFERÊNCIAS}

Boucher, J. (1996). What could possibly explain autism? Em P. Carruthers \& P. K. Smith (Orgs.), Theories of theories of mind (pp. 223-241). Cambridge: Cambridge University Press.

Bradmetz, J. (1998). Is the acquisition of a Theory of Mind linked to a specific competence beyond three years of age? Intelligence, 26, 1-8.

Byrne, R. W. \& Whiten, A. (Orgs.) (1988). Machiavellian intelligence - social expertise and the evolution of intellect in monkeys, apes, and humans. Oxford: Clarendon Press.

Byrne, R. W. \& Whiten, A. (Orgs.) (1997). Machiavellian intelligence II: extensions and evaluations. Cambridge: Cambridge University Press.

Frith, C. D. \& Frith, U. (1999). Interacting minds - a biological basis. Science, 256, 1692-1695.

La Frenière, P. J. (1988). The ontogeny of tactical deception in humans. Em R. Byrne \& A. Whiten (Orgs.), Machiavellian intelligence - social expertise and the evolution of intellect in monkeys, apes and humans (pp. 238-252). Oxford: Clarendon Press.

Phillips, W., Baron-Cohen, S. \& Rutter, M. (1998). Understanding intention in normal development and in autism. British Journal of Developmental Psychology, 16, 337-348.

Premack, D. \& Woodruff, G. (1978). Does a chimpanzee have a theory of mind? The Behavioral and Brain Sciences, 3, 515526.

Premack, D. (1988). "Does a chimpanzee have a theory of mind?" revised. Em R. Byrne \& A. Whiten (Orgs.), Machiavellian Intelligence - Social expertise and the evolution of intellect in monkeys, apes, and humans (pp. 160-179). Oxford: Clarendon Press.

Szarkowicz, D. L. (1999). Young children's false belief understanding during play. The Journal of Genetic Psychology, 160, 243-254.

Vygotsky, L. S. (1984). A formação social da mente. Em M. Cole, V. John-Steiner, S. Scribner \& E. Souberman (Orgs.), Tradução de J. C. Neto, L. S. Menna Barreto e S. C. Afeche. São Paulo: Martins Fontes.

Wellman, H. M., Hollander, M. \& Schult, C. A. (1996). Young children's understanding of thought bubbles and of thoughts. Child Development, 67, 768-788.

Wimmer, H. \& Perner, J. (1983). Beliefs about beliefs: representation and constraining function of wrong beliefs in young children's understanding of deception. Cognition, 13, 103-128. 


\section{Agradecimentos}

Agradecemos à Instituição Creche Oeste da USP, à psicóloga Maria Clotilde de Magaldi (Coordenadora da Divisão de Creches do COSEAS), a Eliete Alves, da E. E. Maestro Fabiano Lozano, à diretora Luiza Cesca, do Colégio Émile de Villeneuve, pela colaboração no acesso às crianças entrevistadas, a Maria de Lourdes Rodriguez pelas ilustrações utilizadas nos experimentos, à FAPESP, pelo apoio financeiro sob a forma de bolsas de Iniciação Científica, e ao CNPq, pela Bolsa de Produtividade em Pesquisa do primeiro autor.

\section{Sobre os autores:}

Eduardo B. Ottoni: Bacharel em Ciências Biológicas (IBUSP, 1983). Doutor em Psicologia Experimental (IPUSP, 1993). Professor Doutor Assistente Departamento de Psicologia Experimental Instituto de Psicologia USP; bolsista CNPq. Endereço eletrônico: eduardo.ottoni@gmail.com.

Cláudia Fernanda Rodriguez: Psicóloga (IPUSP, 2002). Mestre em Psicologia Escolar e do Desenvolvimento Humano (IPUSP, 2005). Endereço eletrônico: claudiafr@uol.com.br.

Janaína Corazza Barreto: Psicóloga (IPUSP, 2003). Mestranda em Psicologia Escolar e do Desenvolvimento Humano (IPUSP). Endereço eletrônico: janacbs@yahoo.com.br.

Endereço para correspondência: Departamento de Psicologia Experimental, Instituto de Psicologia, Universidade de São Paulo - Av. Prof. Mello Moraes, 1.721, Cidade Universitária - 05508-030 São Paulo/SP 